\title{
Modelo Geoelétrico 3D Aplicado à Geotecnia
}

Bruna Teixeira Pandolpho da Costa e Silva* (b.pandolpho@gmail.com) - Instituto de Geociências/Universidade de Brasília Welitom Rodrigues Borges (welitom@unb.com.br) - Instituto de Geociências/Universidade de Brasília

Copyright 2016, SBGf - Sociedade Brasileira de Geofísica

Este texto foi preparado para a apresentação no VII Simpósio Brasileiro de Geofísica, Ouro Preto, 25 a 27 de outubro de 2016. Seu conteúdo foi revisado pelo Comitê Técnico do VII SimBGf, mas não necessariamente representa a opinião da SBGf ou de seus associados. E proibida a reprodução total ou parcial deste material para propósitos comerciais sem prévia autorização da SBGf.

\begin{abstract}
In Brasilia, there is a high incidence of problem soils in relation to the carrying capacity in its natural state compressed, known as porous and collapsible soils. In general, in the entire city area occur clay layers with low strength or load carrying capacity. In order to characterize the soil and its geotechnical properties was conducted a geophysical research with the method of electrical resistivity (dipole-dipole array), in an area where the installation is programmed for a solid waste separation. The results show three layers with different resistivities, for each layer has been assigned a quality factor of excavation to support civil engineering in recognizing and planning the sediment extraction and to find the basement for the building's foundation and its depth.
\end{abstract}

\section{Introdução}

Um estudo geotécnico detalhado contribui com a análise do ambiente da obra, e também prevê em qual aspecto a obra interferirá com o ambiente (Silva, 2001).

O conhecimento das características da zona de transição solo-rocha, da profundidade do topo rochoso e da profundidade do nível d'água, é considerado de extrema importância para o planejamento da ocupação do meio físico. A ciência desses atributos é considerada fundamental para praticamente todos os fatores relacionados à ocupação, como fundações, escavabilidade, disposição de resíduos, estradas, obras enterradas, estabilidade de taludes, erodibilidade, poluição, irrigação e loteamento (Elis e Zuquette, 1995).

A engenharia civil buscou na geofísica um método eficiente, barato e que atingisse grandes profundidades, encontrando na eletrorresistividade uma forma de determinar camadas de solo/rocha e a capacidade que as mesmas possuem para sustentar uma construção civil.

Este trabalho traz uma visão qualitativa da área de estudo quanto ao fator de escavabilidade e sua influência para tomada de decisões de engenharia civil por meio da aplicação do método do caminhamento elétrico com o arranjo dipolo-dipolo na área de Brasília, Distrito Federal, que apresenta solos problemáticos em relação à capacidade de suporte em seu estado natural compactado, conhecidos como solos porosos e colapsáveis, de forma que em quase toda a área urbana ocorre uma camada superficial de argila com baixa resistência ou capacidade de suporte.

A área de estudo se encontra próxima à Cidade do Automóvel (Figura 1), onde programa-se a instalação de uma das seis Centrais de Triagem de separação de resíduos sólidos do Lixão do Jóquei, conhecido como Lixão da Estrutural, em processo de desativação.

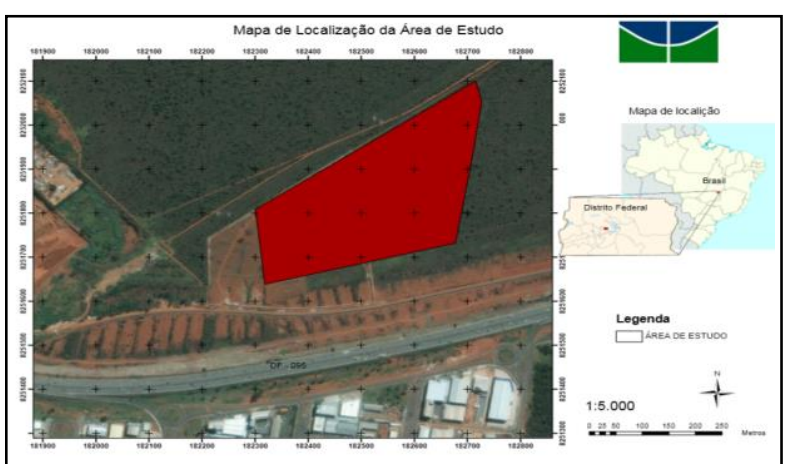

Figura 1 - Localização da área de estudo, próxima à Cidade do Automóvel, em frente à linha férrea. Local destinado à construção de uma central de triagem de resíduos sólidos

\section{Metodologia/ Problema Investigado}

A partir do método da eletrorresistividade, utilizado neste trabalho, investigou-se o subsolo com a indução de correntes elétricas no meio com eletrodos metálicos, e mediu-se a diferença de potencial elétrico com outros dois eletrodos de potencial. Essas medidas possibilitaram a determinação da resistividade elétrica do meio.

No método elétrico, o fluxo de corrente elétrica na subsuperfície é governado pela condutividade elétrica das rochas ali presentes. Segundo Fukue et al. (1999) a resistividade do solo depende, no mínimo, dos seguintes fatores: composição mineralógica, grau de saturação, resistividade do líquido nos poros, porosidade, tamanho, forma e distribuição das partículas sólidas, e espessura e composição da camada catiônica dos argilominerais.

O método elétrico possui várias técnicas de aquisição de dados e uma grande configuração de eletrodos, o que confere ao método grande versatilidade. Os tipos de arranjo no método da eletrorresistividade variam de acordo com a disposição dos eletrodos e espaçamento entre eles. $\mathrm{Na}$ área de pesquisa, optou-se pelo uso da técnica de aquisição de dados conhecida como Caminhamento Elétrico, que possibilita a verificação da variação da resistividade ao longo de uma seção 2D. 
O arranjo Dipolo-Dipolo (Figura 2) é o mais sensível ao topo rochoso do embasamento e com esta disposição adquiriu-se, com o equipamento Syscal Pro 72. Neste trabalho foram utilizadas 8 linhas do Limite Sul (LS) da área de estudo (Figura 3) com espaçamento entre eletrodos igual a $10 \mathrm{~m}$.

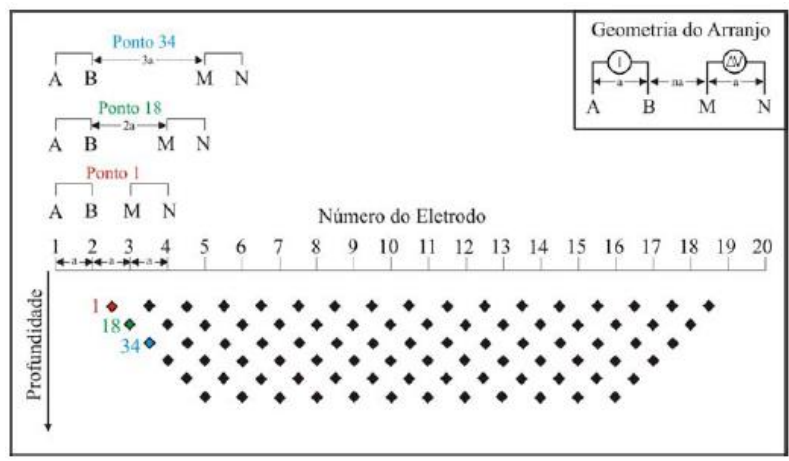

Figura 2 - Arranjo de eletrodos $D D$, espaçamento "a" entre o par de eletrodos de corrente $(A B)$ e entre o par de eletrodos de potencial (MN) com distância entre os dois pares igual a um fator " $n$ " de "a" e a sequência de medidas utilizadas para construir uma pseudoseção (Borges, 2007).

O espaçamento entre as linhas é igual a $20 \mathrm{~m}$ e o processamento das linhas foi feito com o software Prosys II e Res2dinv/Res3dinv, filtrando e gerando os perfis de resistividade $2 \mathrm{D}$ e $3 \mathrm{D}$, respectivamente. $\mathrm{O}$ filtro baseouse nos gráficos de resistividade e de desvio padrão, buscando eliminar dados espúrios de ambos parâmetros.

A partir do software de inversão RES2DINV eliminou-se manualmente dados ruidosos ou dados com ruídos sistemáticos, resultados de falha durante a aquisição. Cabos defeituosos, alta resistência de contato entre o solo e o eletrodo são alguns dos causadores de ruídos sistemáticos. A interpolação por mínimos quadrados contou com células de inversão iguais à metade do espaçamento entre os eletrodos; neste caso, 5 metros, e os valores máximos e mínimos da resistividade foram limitados para se manterem fiéis ao modelo geológico da área, que consiste em regolitos, quartzito e metassiltito.

Ainda com o software RES2DINV as oito linhas foram unidas em um único arquivo, que foi então convertido para arquivo de leitura do software RES3DINV. Neste, os valores máximo e mínimo da inversão foram limitados segundo o valor médio de resistividade dos dados, procurando novamente se manter fiel ao modelo geológico da área.

A partir dos dados interpolados em formato xyz, utilizouse o software Oasis Montaj 7.0.1 para gerar o voxel e então o mapa geolétrico.

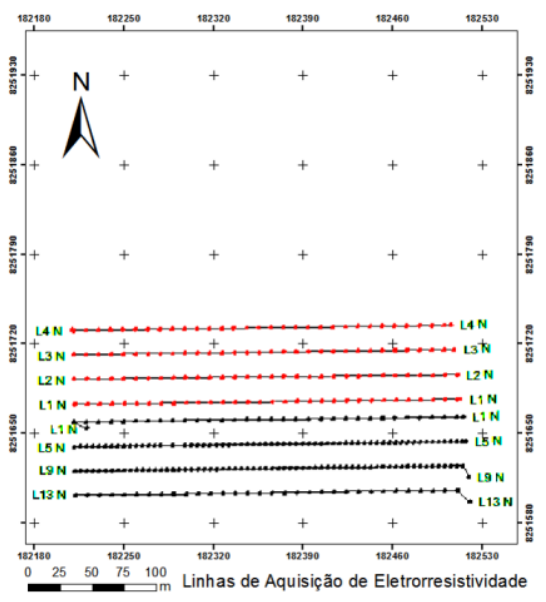

Figura 3 - Disposição das linhas de aquisição dos perfis de eletrorresistividade na área de estudo, próxima à Cidade do Automóvel, Brasília-DF.

\section{Resultados}

O modelo geoelétrico 3D (Figura 4) é composto por três profundidades diferentes e, consequentemente, três características elétricas distintas. A cada uma, atribuiu-se um tipo de escavabilidade associado ao grau de compactação, evidenciado pela resposta do método geofísico.

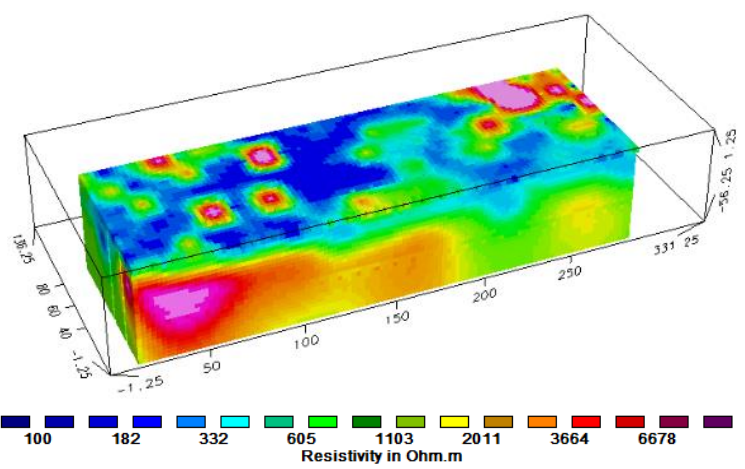

Figura 4 - Modelo geoelétrico $3 D$ completo da área de estudo, próxima à Cidade do Automóvel, Brasília-DF.

As três profundidades delimitadas foram definidas a partir de seus valores de resistividade, sendo a primeira em um intervalo de 0-1500 Ohm.m (Figura 5), a segunda definida de 1500-3000 Ohm.m (Figura 6) e a terceira profundidade de 3000-12000 Ohm.m (Figura 7).

Associado à resistividade, foram utilizadas as respectivas características geoelétricas. $O$ primeiro perfil pode ser entendido como a camada mais superficial, principalmente como solo com baixa resistividade; característica do solo argiloso encontrado na área de estudo. O segundo perfil compreende uma camada intermediária, que separa o solo do embasamento rochoso e é aqui caracterizado como regolito. Por fim, a 
camada mais resistiva é compreendida como o embasamento rochoso, devido à sua alta resistividade, uma vez que estas apresentam alto grau de compactação.

De forma qualitativa, neste trabalho será utilizada a denominação "fator de escavabilidade" para distinguir o trabalho necessário para que se alcance o embasamento rochoso e se instale a fundação dos futuros prédios a serem instalados na área. O fator escavabilidade foi dividido em três tipos: alto (I), médio (II) e baixo (III).

Tipo I (Figura 5), de fácil escavação, não necessita maquinário e pode ser classificado como escavação manual, correspondendo à primeira característica geoelétrica, baixa resistividade, solo. O tipo II (Figura 6), média escavabilidade, necessita o uso de máquinas para escavação, escavação maquinaria referente a valores médios de resistividade, regolito. Tipo III (Figura 7), baixa escavabilidade, é preciso explosivos para sua escavação, servindo como base para os apoios das fundações.

\section{Discussão e Conclusões}

A eletrorresistividade como forma de determinação de fatores de escavabilidade, imprime na engenharia civil um aspecto importante para a determinação da profundidade do embasamento rochoso, cálculo estimado de volume a ser retirado a fim de se alcançar o embasamento e os locais preferíveis para a fundação dos prédios, sendo essas as áreas mais resistivas, mais compactadas e menos colapsáveis.

Os cálculos de profundidade do topo do embasamento rochoso, $15 \mathrm{~m}$ para este trabalho, e volume de material de extração necessário para se alcançar a parte mais resistente é ideal para a base das construções de engenharia civil. Esse conjunto de informações permite um maior e melhor planejamento, a fim de diminuir custos, impactos ambientais, futuros desmoronamentos e maior longevidade das obras implementadas.

\section{Agradecimentos}

Agradecimentos à empresa InterGeo pela aquisição dos dados geofísicos, à FAPDF (Projeto InterGeo/FAPDF Contrato 012/2013) pela cessão dos dados geofísicos, ao Laboratório de Geofísica Aplicada (LGA) e ao Técnico Péricles Macedo pelo apoio em campo.

\section{Referências}

Borges, W.R. (2007). Caracterização Geofísica de Alvos Rasos com Aplicações no Planejamento Urbano e Meio Ambiente: Estudo sobre o Sítio Controlado do IAG/USP. Universidade de São Paulo, SP, 271p.

Elis, V. R. \& Zuquette, L. V (1996). Caminhamento elétrico dipolo-dipolo- In: Congresso Brasileiro de Geologia de Engenharia, 8, Rio de Janeiro, RJ. Anais. Rio de Janeiro, RJ: ABGE, 1996, v-1, 10 p.
Fukue, M.; Minato, T.; Horibe, H. \& Taya, N. 1999. The micro-structures of clay given by resistivity measurements. Engineering Geology,54: 43-53.

Silva, C.P.L. (2011). Cartografia Geotécnica Tridimensional do Setor Noroeste de Brasília. Tese de Doutorado, Publicação G.TD-072/2011, Departamento de Engenharia Civil e Ambiental, Universidade de Brasília, Brasília, DF, 265 p.

Zuquette, L. V. (1987). Análise Crítica sobre Cartografia Geotécnica e Proposta Metodológica para as Condições Brasileiras. Tese de doutorado, EESC/USP, São Carlos,

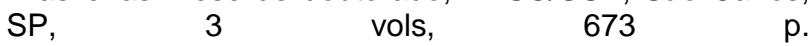




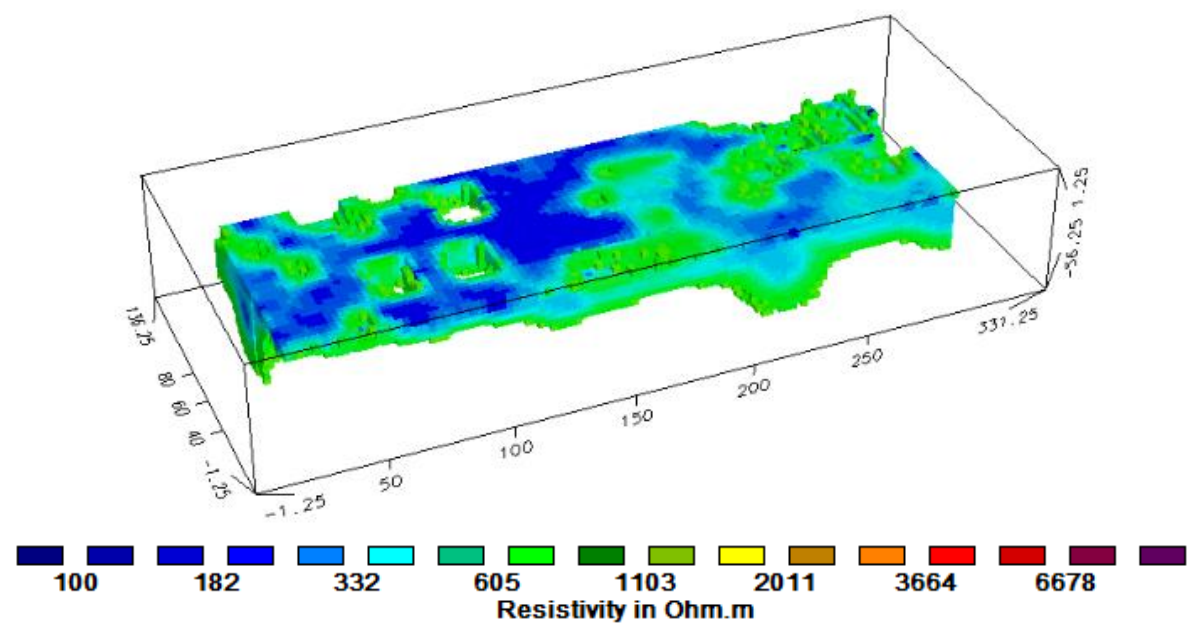

Figura 5 - Modelol geoelétrico de intervalo 0 a 1500 Ohm.m, caracterizado por baixa resistividade, solo, e alta escavabilidade, por sua fácil extração, sem uso de maquinário.
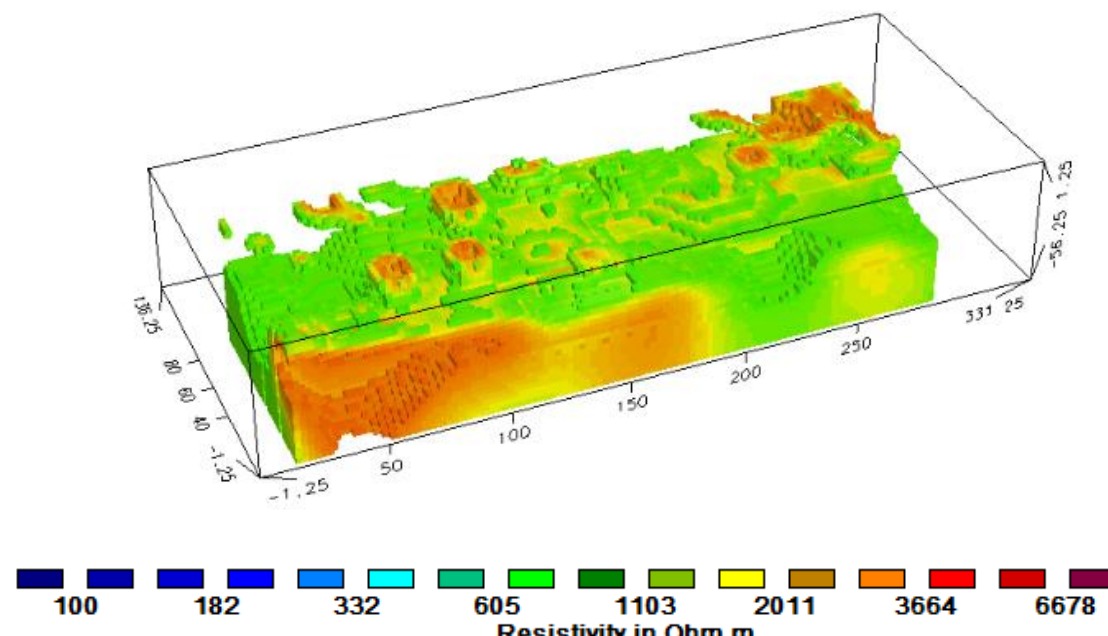

Figura 6 - Modelo geoelétrico de intervalo 1500 a 3000 Ohm.m, caracterizado por média resistividade, regolito, e média escavabilidade, por sua média extração, com uso de maquinário.

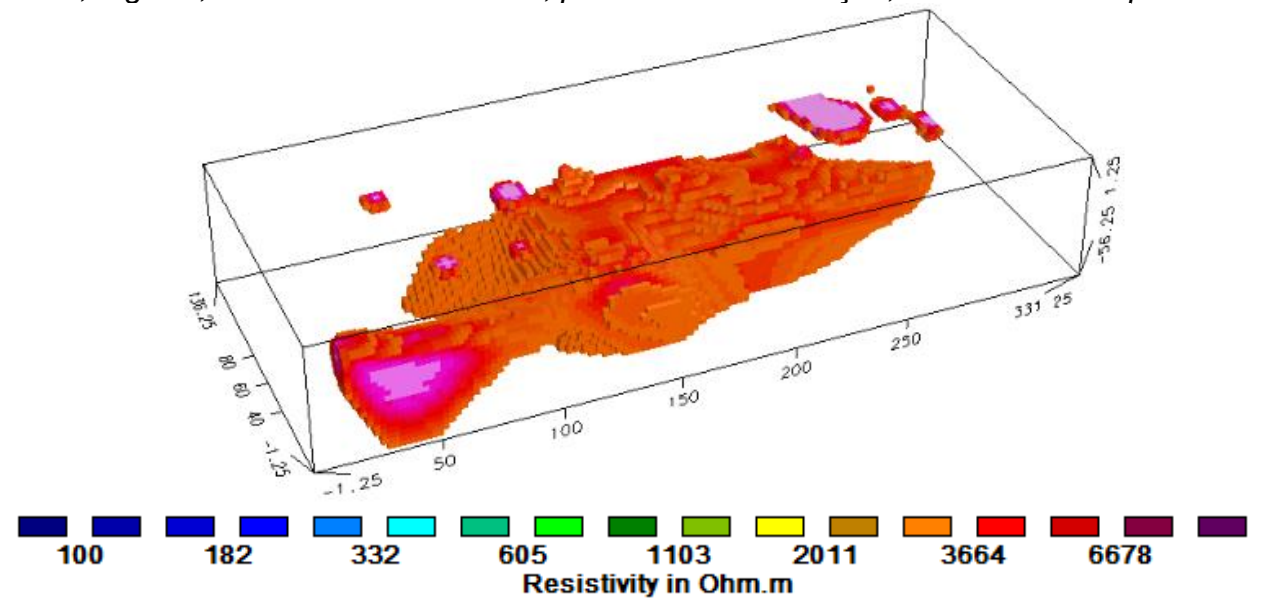

Figura 7 - Modelo geoelétrico de intervalo 3000 a 12000 Ohm.m, caracterizado por alta resistividade, embasamento rochoso e baixa escavabilidade, por sua baixa facilidade de extração, necessidade de explosivos. Ideal para fixação de fundações para a engenharia civil. 